\title{
PERANCANGAN DESAIN VELG SEPEDA MOTOR HYBRID DAN PENGUJIAN DISTRIBUSI BEBAN DENGAN SOFTWARE AUTODESK INVENTOR
}

\author{
Eko Arif Syaefudin ${ }^{1}$, Imam Basori ${ }^{2}$ \\ Jurusan Teknik Mesin, Fakultas Teknik, Universitas Negeri Jakarta \\ Jl. Rawamangun Muka, Jakarta Timur, Indonesia, 13220 \\ Email: eko_arif_syafudin@yahoo.com \\ Dosen Teknik Mesin Universitas Negeri Jakarta ${ }^{(1),(2)}$
}

\begin{abstract}
ABSTRAK
Sepeda motor hybrid merupakan salah satu solusi alternatif saat ini dalam mengatasi keterbatasan bahan bakar minyak yang tidak dapat diperbaharui. Hybrid adalah teknologi yang menggabungkan dua atau lebih tenaga penggerak dalam satu kendaraan. Sepeda motor hybrid ini menggunakan dua macam tenaga penggerak yaitu mesin berbahan bakar minyak dan motor listrik. Penelitian ini bertujuan untuk mengadaptasi teknologi hybrid agar bisa digunakan pada sepeda motor. Dalam menerapkan sepeda motor hybrid ini, diperlukan beberapa perubahan komponen, salah satu diantaranya adalah velg. Perubahan velg ditujukan agar motor listrik sebagai penggerak sepeda motor dapat dimasukkan ke dalam velg. Desain velg ini sangat penting agar perubahan velg ini bisa diaplikasikan pada sepeda motor yang telah digunakan masyarakat. Desain tersebut dibuat menjadi dua tipe, yaitu velg jari-jari (spoke wheel) dan velg racing (cast alloy wheel) yang berdiameter 17 inchi dan digunakan untuk sepeda motor jenis moped (bebek).

Pembuatan desain velg ini menggunakan software Autodesk Inventor. Dalam program Autodesk Inventor, meliputi fitur untuk desain 3 dimensi dan 2 dimensi. Model dan dimensi juga dapat dibuat secara akurat dan tepat.sehingga ketika akan dianalisis dapat menghasilkan data yang tepat. Velg yang dibuat adalah jenis velg jari-jari dan velg racing dengan perbedaan variasi tiap velg. Desain velg ini kemudian diuji untuk mengetahui kekuatan yang dapat ditahan oleh velg jika diberi beban baik dalam keadaan diam (statis) maupun bergerak (dinamis). Beban yang diberikan merupakan beban kendaraan ditambah beban penumpang. Pada pengujian ini beban yang diberikan dalam keadaan statis mulai dari $1.500 \mathrm{~N}$ hingga $3.000 \mathrm{~N}$ dengan kelipatan $250 \mathrm{~N}$ sedangkan untuk pengujian dinamis, beban yang diberikan sebesar $3.000 \mathrm{~N}$ dan momen mulai dari 5.000 N.mm hingga 30.000 N.mm dengan kelipatan 5.000 N.mm.

Pengujian ini menggunakan software Autodesk Inventor, yang dapat menyesuaikan material tiap komponen sesuai dengan material yang dianjurkan. Dengan menghitung faktor keamanan tiap velg, tegangan luluh (Yield strength) dibagi dengan tegangan Von Mises maksimum, pada pengujian statis, semua velg memiliki faktor keamanan lebih dari 1,0. Pada pengujian dinamis, didapatkan hasil velg jari-jari tipe E dengan jumlah jari-jari 64 buah adalah velg yang tepat digunakan sebagai velg sepeda motor hybrid. Faktor keamanan pada velg tipe E memiliki nilai 1,457. Velg ini menggunakan material steel yang memiliki Yield strength sebesar 207 MPa dan tegangan Von Mises maksimum sebesar 141,999 MPa.
\end{abstract}

Kata kunci: desain velg, sepeda motor hybrid, software Autodesk Inventor

\section{PENDAHULUAN}

Sepeda motor merupakan sarana transportasi yang sangat penting dalam era modern seperti saat ini, karena itu jumlah sepeda motor semakin meningkat. Hal ini dapat dilihat dengan semakin padatnya lalulintas walaupun pembangunan sarana lalu lintas selalu ditingkatkan. Semakin meningkatnya kebutuhan transportasi, menyebabkan pemakaian bahan bakar minyak yang besar. Bahan bakar minyak merupakan sumber daya alam yang tidak dapat diperbaharui sehingga jika pemakaiannya semakin bertambah maka jumlah bahan bakar akan semakin berkurang. Untuk mengatasi permasalahan tersebut, sekarang banyak dikembangkan kendaraan yang dapat mengurangi konsumsi bahan bakar minyak, salah satunya adalah kendaran hybrid. 
Hybrid dapat dijadikan solusi alternatif dalam menekan konsumsi bahan bakar dan juga mengurangi emisi gas buang. Kendaraan hybrid memadukan dua macam penggerak yaitu mesin berbahan bakar minyak dan motor listrik. Pada kondisi tertentu, yang tidak terlalu membutuhkan kecepatan dan akselerasi yang tinggi atau pada kondisi jalan yang tidak berkontur tinggi-rendah juga pada lalulintas yang padat, kendaraan dapat menggunakan penggerak motor listrik sehingga mesin berbahan bakar minyak tidak bekerja (mati), sebaliknya pada saat mesin berbahan bakar minyak bekerja, putaran roda kendaraan dapat dimanfaatkan sebagai pengisi daya untuk motor listrik. Hal ini yang menjadi kelebihan dari kendaraan hybrid. Saat ini banyak pihak yang sudah melakukan riset bahkan telah menghasilkan prototype meskipun masih membutuhkan banyak penyempurnaan.

Sepeda motor bisa dikembangkan menjadi kendaraan hybrid. Tentunya dengan melakukan perubahan pada beberapa komponennya, yaitu velg, agar dapat dipasang sebuah motor listrik yang dapat menggerakkan sepeda motor tersebut. Velg merupakan penunjang sekaligus tempat dimana ban terpasang. Velg dapat dibuat dalam berbagai proses, salah satu diantaranya adalah pengecoran Velg merupakan salah satu komponen otomotif yang terus mengalami kemajuan desain dan banyak mengutamakan estetika.

Oleh karena itu, perlu dilakukan penelitian mengenai jenis velg yang tepat untuk digunakan pada sepeda motor hybrid. Penelitian ini sangat penting agar dalam mendesain velg sepeda motor hybrid, bisa ditentukan bahan, model, dimensi, dan parameter lain yang dapat menunjang kemampuan, ketahanan, serta penampilan yang baik bagi sepeda motor hybrid.

\section{METODE PENELITIAN}

Metode penelitian yang digunakan adalah metode penelitian eksperimen. Untuk mendapatkan gambar velg yang sesuai dengan aslinya, velg diukur secara manual dengan teliti, setelah itu, velg digambar dengan menggunakan software Autodesk Inventor. Pengujian dilakukan dengan menggunakan software tersebut yang berbasis Metode Elemen Hingga yang mampu menyelesaikan persoalan-persoalan struktur dan material untuk menganalisis tegangan (stress), getaran (vibration), dan distribusi beban velg dalam berbagai kondisi. Metode Elemen Hingga digunakan karena metode ini menggunakan pendekatan yang berasumsi peralihan atau asumsi tegangan atau berdasarkan kombinasi keduanya pada setiap elemennya. Simulasi komputer dilakukan untuk mengklarifikasi perlakuan mekanik yang terjadi akibat pengujian secara eksperimental.

Tahap penelitian dalam penelitian ini dapat digambarkan dengan bagan aliran proses penelitian sebagai berikut:

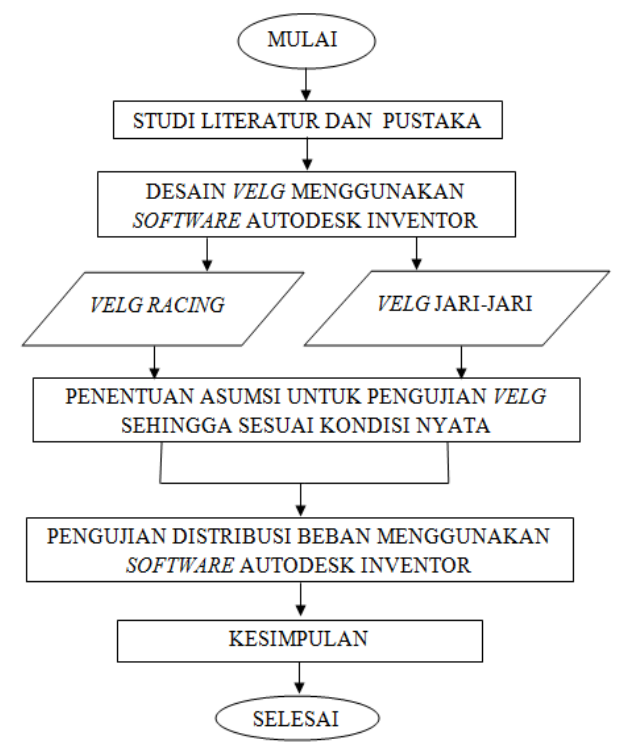

Gambar 1. Diagram Alir Penelitian

\section{a. Desain Velg}

Pemodelan dalam penelitian ini meliputi pemodelan dengan penerapan metode elemen hingga dengan bantua software Auteodesk Inventor, yang bertujuan untuk melakukan analisis tegangan dan deformasi yang terjadi pada velg.

Pada penelitian ini, desain velg dibuat menjadi dua macam, yaitu velg jari-jari (spoke wheel) dan velgracing (cast alloy wheel). Dari dua tipe velg tersebut juga dibuat beberapa model untuk mendapatkan variasi data sehingga pada tahap pengujian bisa ditentukan tipe dan model velg apa yang mempunyai hasil maksimal. Desain tersebut juga diadaptasi dari velg yang beredar di pasaran dan umum digunakan pada sepeda motor. Dalam pembuatan desain velg, memerlukan beberapa langkah, diantaranya :

Pada layar awal komputer, pilih icon dari Autodesk Inventor, kemudian klik kiri, maka program akan terbuka.

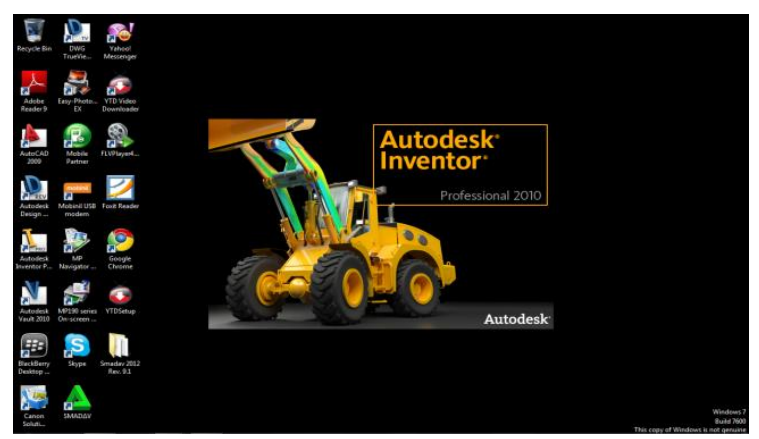

Gambar 2. Membuka Autodesk Inventor 
Setelah program terbuka, akan tampil menu awal. Untuk membuat lembar kerja baru, klik New - Metric - Standard (mm).ipt. Kemudian akan tampil lembar kerja baru.

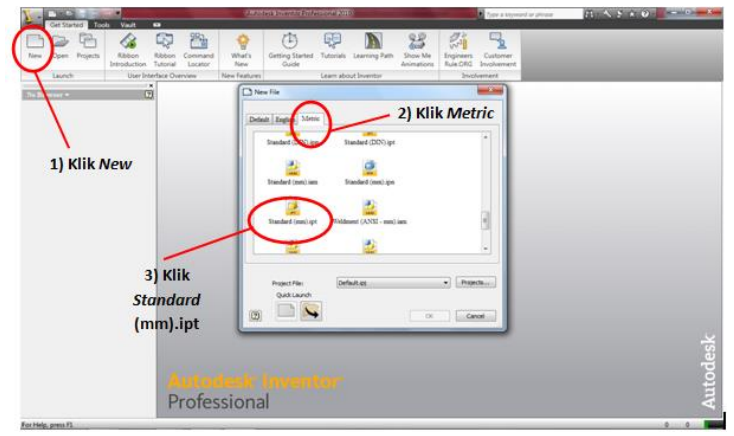

Gambar 3. Membuat File Kerja Baru

Setelah File baru muncul, langkah selanjutnya adalah membuat sketsa velg tersebut. Dengan mempelajari terlebih dahulu software Autodesk Inventor, maka dapat dibuat desain yang sesuai dengan kebutuhan penelitian. Desain yang digunakan dalam penelitian ini sebanyak 14 tipe terdiri dari 7 tipe velg jari-jari dan 7 tipe velg racing. Selain velg, dalam penelitian ini juga mendesain komponen pendukung velg sepeda motor hybrid. Berikut ini adalah hasil dari desain yang dibuat, yaitu:

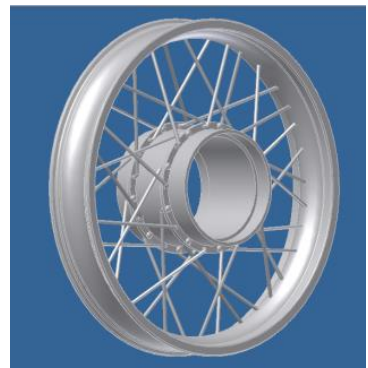

(a)

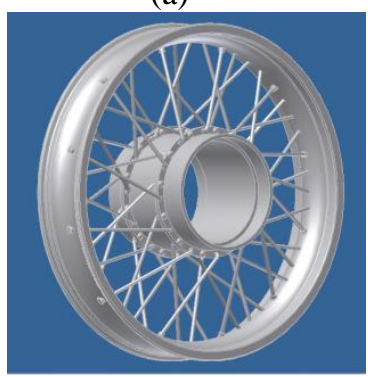

(c)

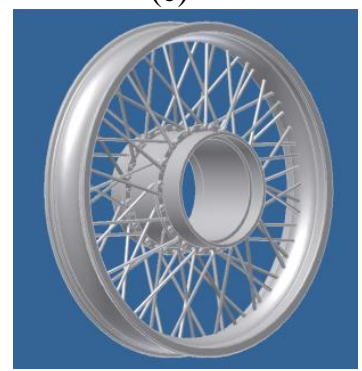

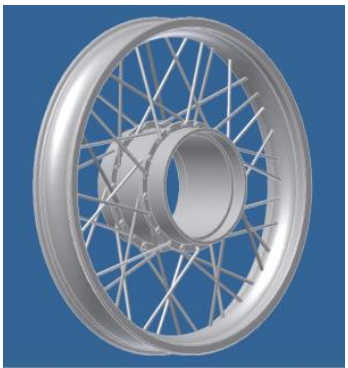

(b)

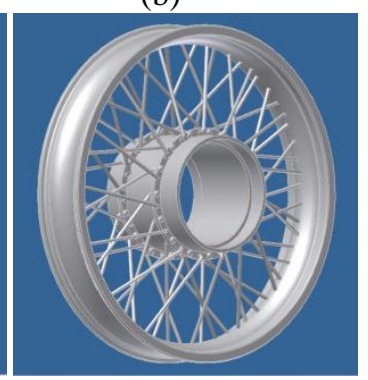

(d)

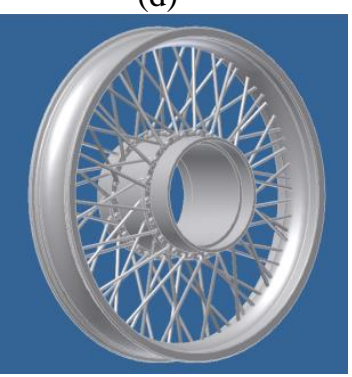

(e)

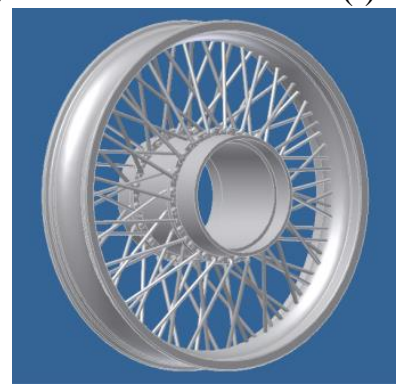

(g)

Gambar 4. Velg Jari-jari (a) Tipe A (b) Tipe B (c) Tipe C (d) Tipe D (e) Tipe E (f) Tipe F (g) Tipe G

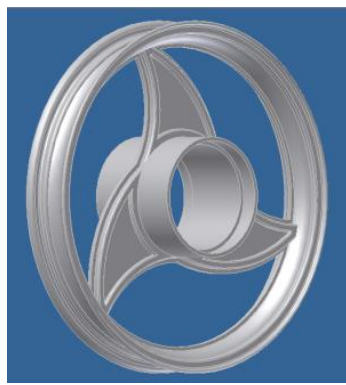

(a)

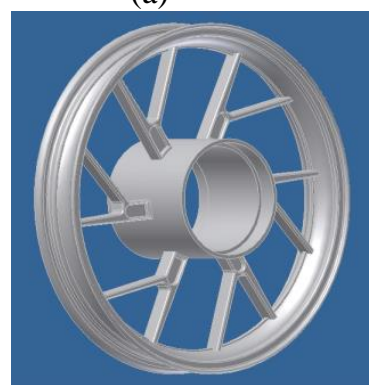

(c)

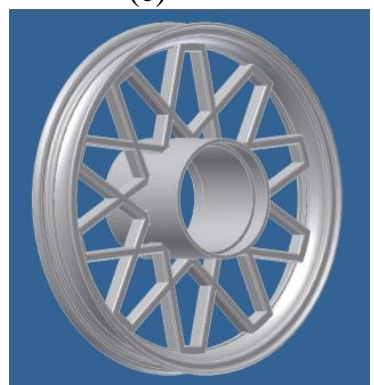

(e)

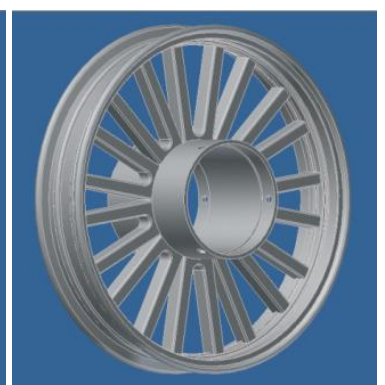

(b)

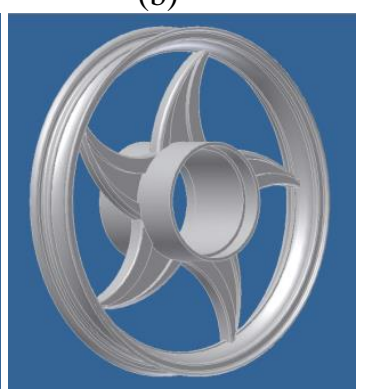

(d)

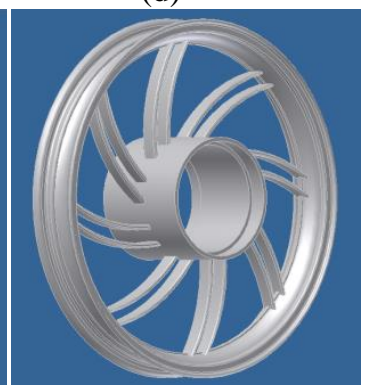

(f)

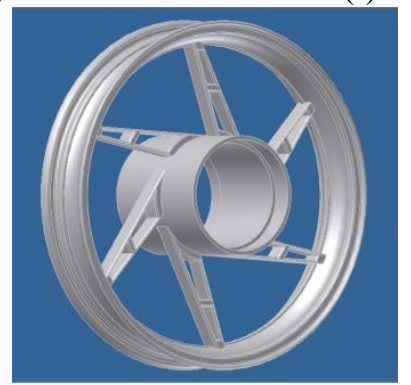

(g)

Gambar 5. Velg Racing (a) Tipe H (b) Tipe I (c) Tipe J (d) Tipe K (e) Tipe L (f) Tipe M (g) Tipe N 


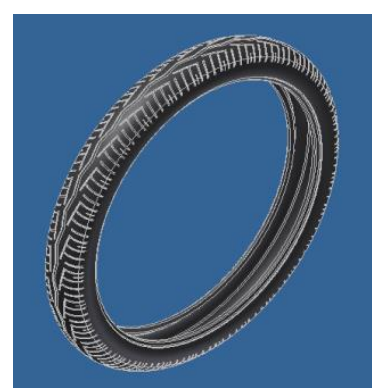

(a)

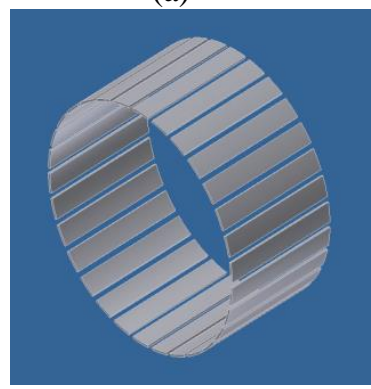

(c)

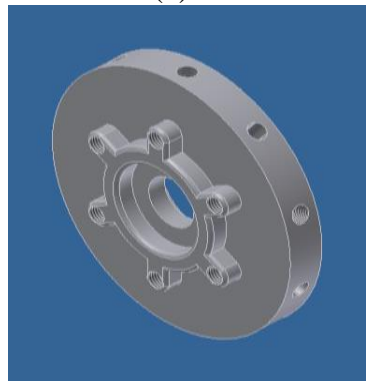

(e)

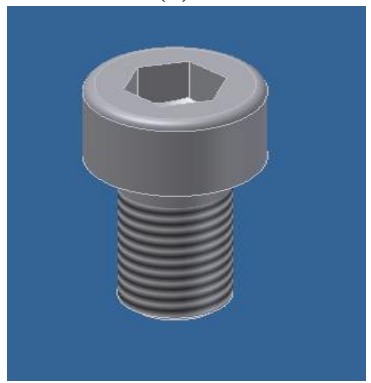

(g)

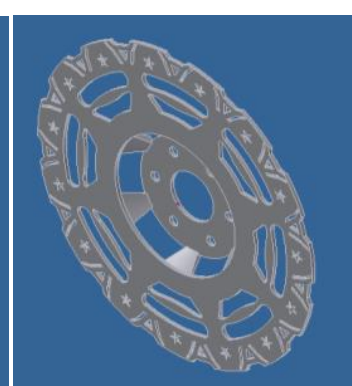

(b)

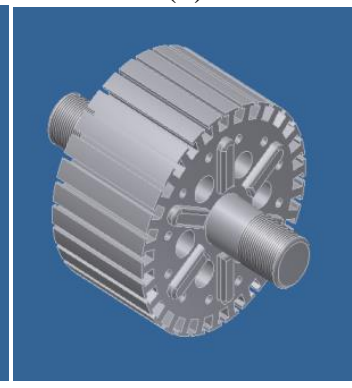

(d)

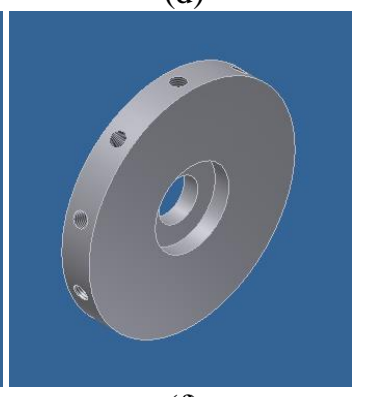

(f)

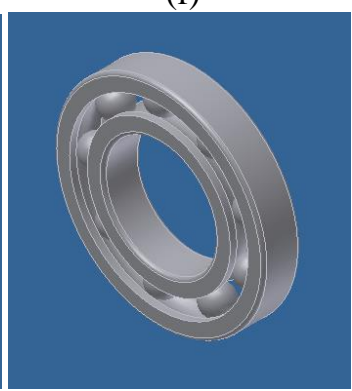

(h)
Gambar 6. Komponen Pendukung (a) Ban (b)Piringan Cakram (Disk) (c) Magnet (dipasang pada tromol velg) (d) Stator Motor Listrik (e) Tutup Tromol Bagian Kanan (f) Tutup Tromol Bagian Kiri (g) Mur Tipe DIN EN ISO $4762 \mathrm{M}$ $10 \times 20$

(h) Bearing SKF Series EE 10

\section{b. Pemilihan Material Komponen}

Pada software Autodesk Inventor, gambar yang telah didesain dapat langsung ditentukan material yang akan digunakan dengan menyesuaikan material yang dianjurkan. Pemilihan material yang digunakan, menggunakan cara yang sama untuk semua benda yang digambar. Tiap komponen yang didesain sudah ditentukan material yang akan digunakan berdasarkan sumber yang telah dianjurkan.

Material pada tiap komponen adalah sebagai berikut; velg jari-jari, tutup tromol kanan, tutup tromol kiri, cakram, magnet, dan stator listrik menggunakan material Steel-Metal Steel; ban menggunakan material Rubber-Nylon Composite (karena tidak seluruh bagian ban dibuat dengan bahan karet); sedangkan untuk velgracing menggunakan material Aluminum (Cast)Aluminum 6061. Klik As Material lalu pilih material yang sesuai dengan benda yang digambar. Klik Physical Properties untuk mengetahui struktur material serta property lain yang dapat dilihat dengan detil.

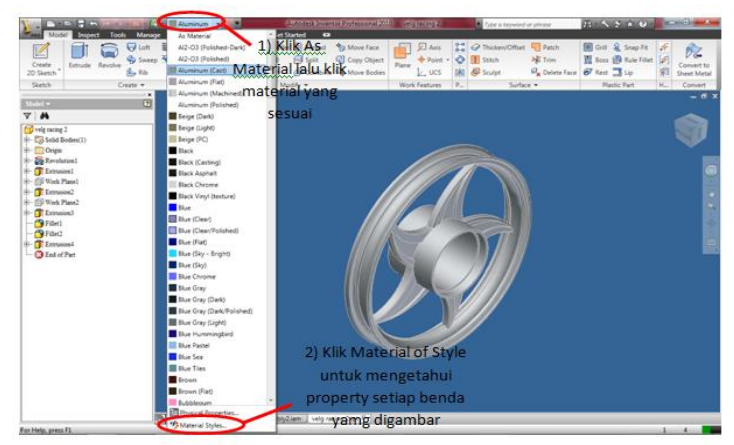

Gambar 7. Pemilihan Material Komponen

\section{c. Assembly Komponen}

Setelah seluruh komponen dibuat secara terpisah (part), langkah selanjutnya adalah menyatukan komponen tersebut. Langkah awal adalah klik bagian pojok kiri atas (lambang Autodesk Inventor) - New - Assembly.

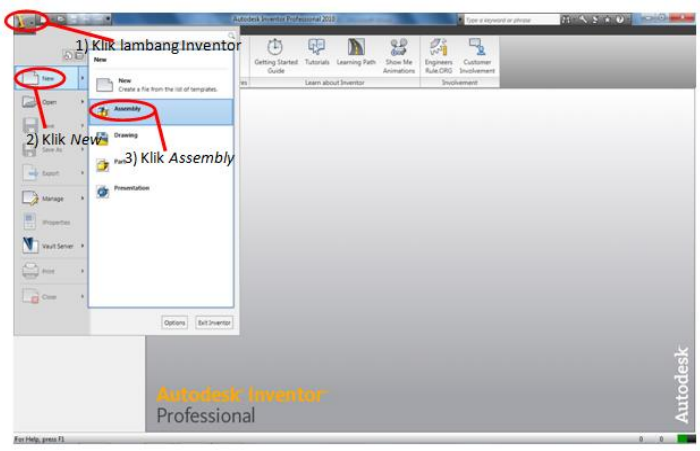

Gambar 8. (a) Langkah 1 membuat assembly komponen

Klik Place - muncul kotak dialog PlaceComponent - pilih gambar - gambar akan terlihat - klik Open. Maka gambar akan muncul di layar sketsa. 


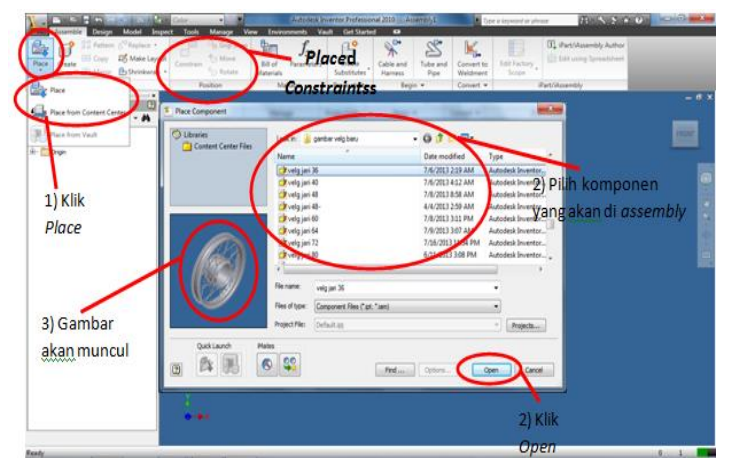

Gambar 8. (b) Langkah 2 membuat assembly komponen

Setelah gambar muncul, ulangi langkah yang sama untuk menyatukan komponen-komponen tersebut menjadi suatu kesatuan, maka seluruh komponen akan menjadi seperti gambar dibawah ini.

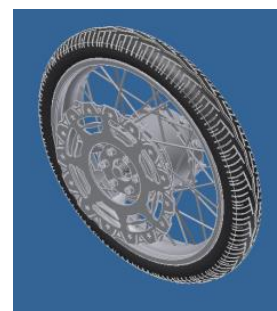

(a)

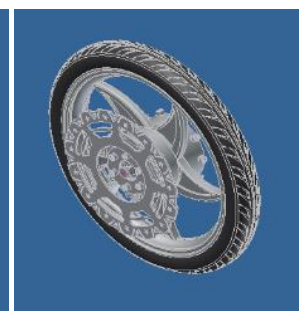

(b)
Gambar 9. (a) AssemblyVelg Jari-jari (Spoke wheel)

(b) AssemblyVelgRacing (Cast alloy wheel)

\section{d. Pengujian Distribusi Beban}

Pengujian dilakukan dengan menggunakan software Autodesk Inventor dengan cara memberikan pembebanan tipe Force (beban statis) dan Force + Moment Load (beban dinamis), untuk dapat diketahui deformasi total maksimum yang dat dicapai oleh velg tersebut sama dengan hasil yang yang diperoleh software tersebut.

Untuk melakukan pengujian beban pada gabungan gambar tersebut, dapat dilakukan beberapa langkah. Langkah-langkah pengujian ini sama baik pengujian pada velg jari-jari maupun velgracing. Klik Environment - Stress analysis CreateSimulation - lalu klik OK.

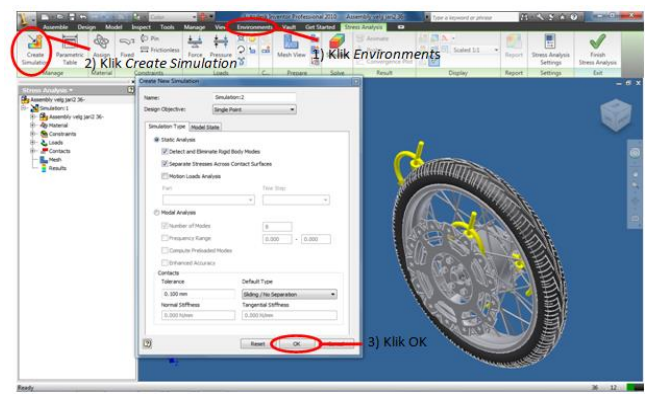

Gambar 10. (a) Langkah 1 Pengujian distribusi beban
Klik Parametric Tabel - klik kanan pada kotak yang muncul klik semua property yang ingin diketahui mulai dari Von Moises Stress hingga Volume. Klik OK, lalukan hal yang sama untuk setiap poperti.

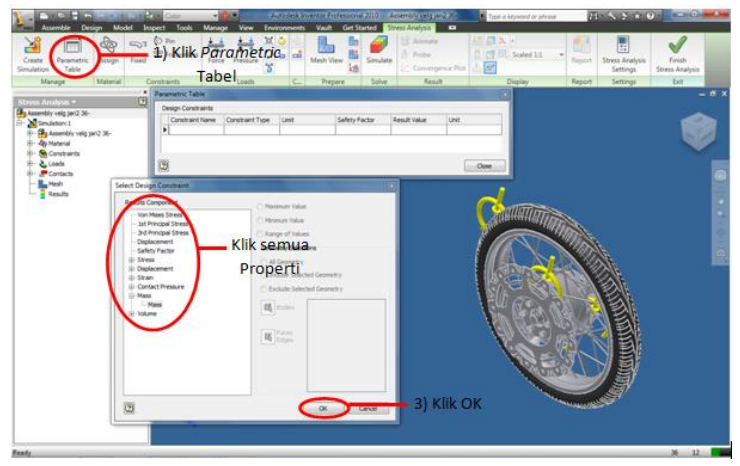

Gambar 10. (b) Langkah 2 Pengujian distribusi beban

Klik Assign - Overwide Material - pilih material sesuai dengan gambar yang dibuat. Klik Style Editor - sesuaikan material dengan benda Done. Setelah selesai, klik OK.

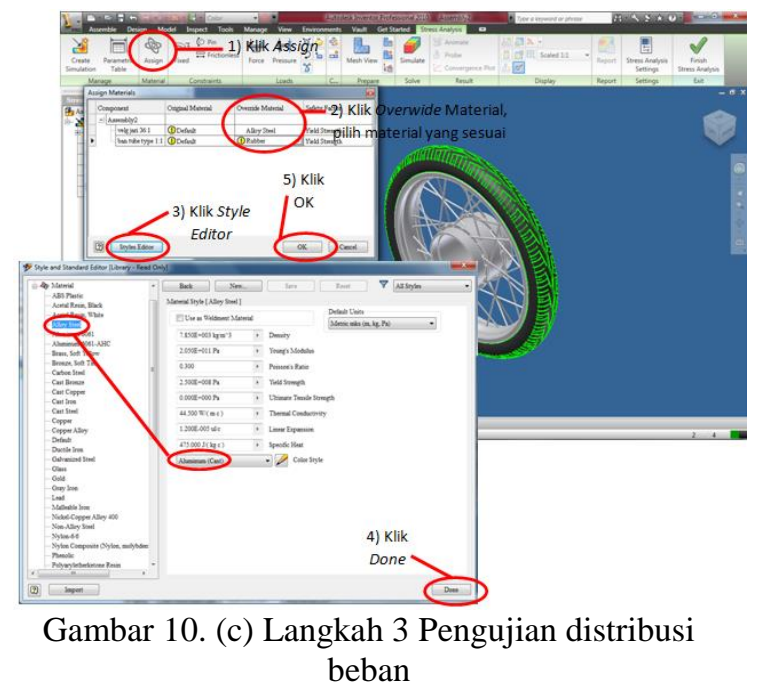

Pada gambar penelitian ini menggunakan dua jenis constraintss yaitu FixedConstraintss (digunakan pada bagian yang bergerak secara translasional) dan PinConstraints (digunakan pada bagian yang berada pada posisi radial, aksial dan tangensial).Langkahnya dengan klik FixedConstraintss dan PinConstraintss pada bagian seperti dijelaskan pada gambar dibawah ini. Langkah ini dilakukan pada kedua jenis velg. 


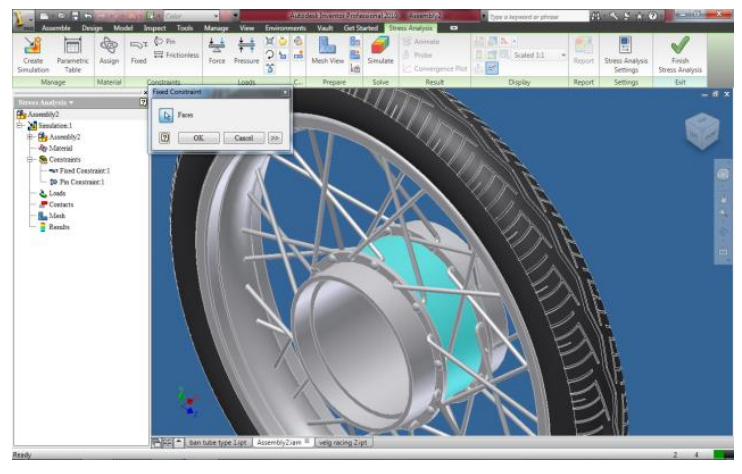

Gambar 10. (d) Langkah 4 Pengujian distribusi beban

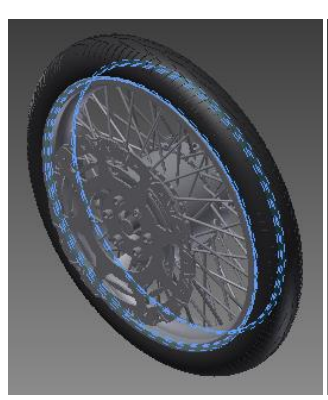

(a)

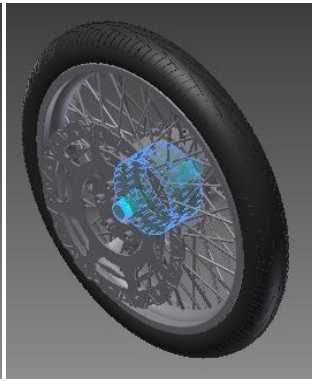

(b)

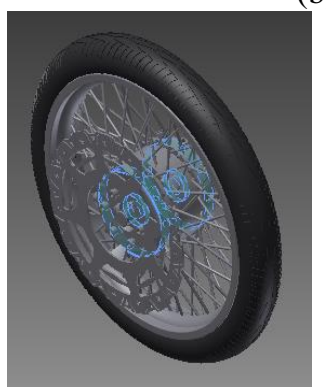

(c)

Gambar 11. Constraints pada Analisis Force,

(a) FixedConstraints

(b) PinConstraints 1 (c) PinConstraints 2

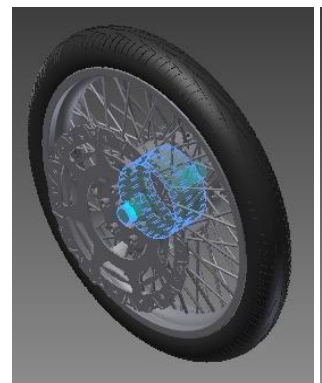

(a)

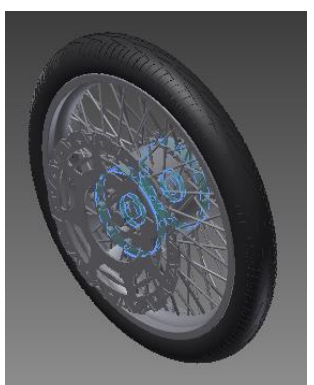

(b)
Gambar 12. Constraints pada Analisis Force,

(a) PinConstraints 1

(b) PinConstraints 2

Masukkan beban yang akan diuji. Beban tersebut meliputi beban sepeda motor dan penumpang. Beban yang digunakan menggunakan satuan Newton (N). Berdasarkan pencarian dari beberapa sumber, berat rata-rata orang Indonesia berkisar mulai dari $50 \mathrm{~kg}$ ke atas. Oleh karena itu, beban yang digunakan yaitu berat sepeda motor dengan satu penumpang dan berat sepeda motor dengan dua penumpang sehingga beban yang dimasukkan dalam penelitian ini dimulai dengan perhitungan sebagai berikut:

\section{1) Force (Gaya)}

Beban ini digunakan pada bagian permukaan, tepi, dan bagian yang melingkar. Jika digunakan pada lebih dari satu macam, maka gaya yang bekerja nilainya sama. Gaya ini diletakkan pada bagian tromol velg dan ban. Gaya yang dipakai pada penelitian ini nilainya sebagai berikut:

$103 \mathrm{~kg}$ (sepeda motor) $+50 \mathrm{~kg}$ (berat penumpang) $=153 \mathrm{~kg}$.

$1 \mathrm{~kg}=2,20 \mathrm{lb}\left(\mathrm{g}=9,81 \mathrm{~m} / \mathrm{s}^{2}\right)$

$1 \mathrm{lb}=4,45 \mathrm{~N}$

sehingga $153 \mathrm{~kg}=153 \times 2,20=336,6 \mathrm{lb}$

$336,6 \mathrm{lb}=336,6 \times 4,45=1497,87 \mathrm{~N}=$ dibulatkan menjadi $1500 \mathrm{~N}$

Oleh karena itu, pembebanan Force pada penelitian ini dimulai dengan angka $1500 \mathrm{~N}$ hingga $3000 \mathrm{~N}$ dengan kelipatan $250 \mathrm{~N}$ untuk menambah variasi penelitian.

\section{2) Moment (Momen)}

Tipe pembebanan ini digunakan pada bagian permukaan yang berbentuk lingkaran dan tegak lurus terhadap sumbu $\mathrm{x}, \mathrm{y}$, atau $\mathrm{z}$. Momen ini diletakkan pada bagian tromol velg dan ban. Pada penelitian ini, momen yang digunakan nilainya sebagai berikut:

Berdasarkan penelitian sebelumnya, kecepatan maksimum yang dapat dilakukan motor listrik untuk sepeda motor listrik mulai dari $50 \mathrm{~km} / \mathrm{jam}$.

Kecepatan $=\mathrm{V}=50 \mathrm{~km} / \mathrm{jam}=50 \times \frac{1000}{3600}=13,8 \mathrm{~m} / \mathrm{s}$ $=$ dibulatkan menjadi $14 \mathrm{~m} / \mathrm{s}$

Jari-jari velg $=\mathrm{r}=285 \mathrm{~mm}=0,285 \mathrm{~m}$

$$
\omega=\frac{V}{r}
$$

$\omega=$ Kecepatan sudut $(\pi \mathrm{rad} / \mathrm{s})=\frac{14}{0,285}=49,12 \pi$ $\mathrm{rad} / \mathrm{s}=49 \pi \mathrm{rad} / \mathrm{s}$

$1 \mathrm{rad} / \mathrm{s}=\frac{60}{2 \pi} \mathrm{rpm}$

$49 \pi \mathrm{rad} / \mathrm{s}=49 \pi \times \frac{60}{2 \pi}=1470 \mathrm{rpm}$

Daya motor listrik $=\mathrm{P}=500$ watt

$$
\mathrm{P}=\frac{\mathrm{T}}{\omega}
$$

Momen Torsi $=\mathrm{T}=\frac{\mathrm{P}}{\omega}^{\omega}=\frac{500}{49}=10,2$ N.m $=$ dibulatkan menjadi 10 N.m $=10.000$ N.mm

Oleh karena itu, momen yang digunakan pada penelitian ini mulai dari 10.000 N.mm dengan kelipatan 5000 N.mm untuk menambah variasi penelitian dengan tetap menyertakan beban tipe Force sebesar $3000 \mathrm{~N}$.

Untuk melakukan pengujian beban, klik Force- klik pada tengah-tengah ban dan bagian tromol velg- masukkan beban (dalam $\mathrm{N}$ ) - OK. 
Untuk pengujian momen, Force tetap digunakan ditambah dengan Momen dengan cara klik Momen - klik pada tengah-tengah ban dan bagian tromol velg. Maka akan muncul tanda pembebanan (tanda panah). Pembebanan diberikan dengan arah 28ertical ke bawah terhadap roda. Langkah ini dilakukan untuk kedua jenis velg. Gambar pembebanan akan ditunjukkan pada gambar dibawah ini.

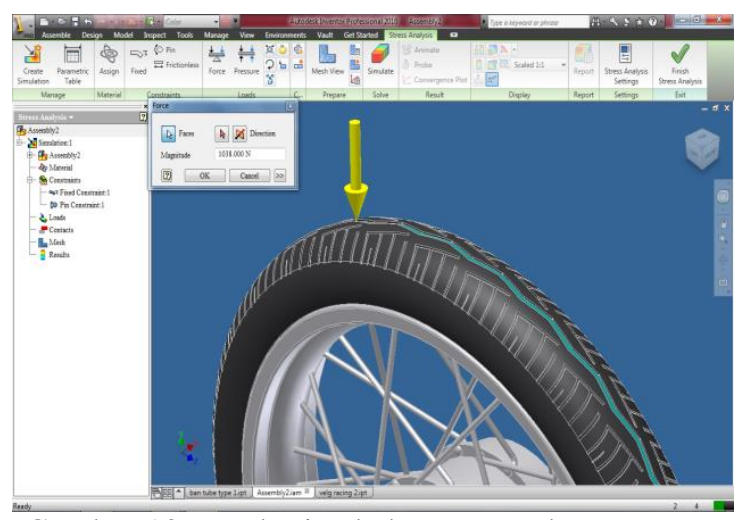

Gambar 13. Pemberian beban Force dan Moment

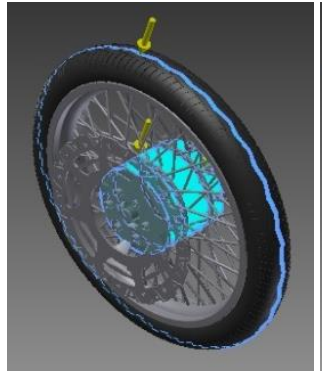

(a)

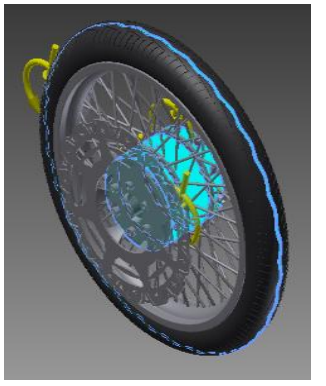

(b)
Gambar 14. Pembebanan pada Analisis (a) Force

(b) Force dan Moment

Setelah selesai, klik MeshView. Gambar akan berubah menjadi potongan-potongan kecil. Hal ini merupakan perhitungan yang dilakukan secara metode elemen hingga. Metode ini digunakan untuk mendapatkan hasil perhitungan yang lebih akurat dibandingkan dengan perhitungan manual karena ada beberapa hal yang sulit dilakukan dengan perhitungan manual seperti luas, berat, volume, dan hal lain dari gambar yang dibuat.

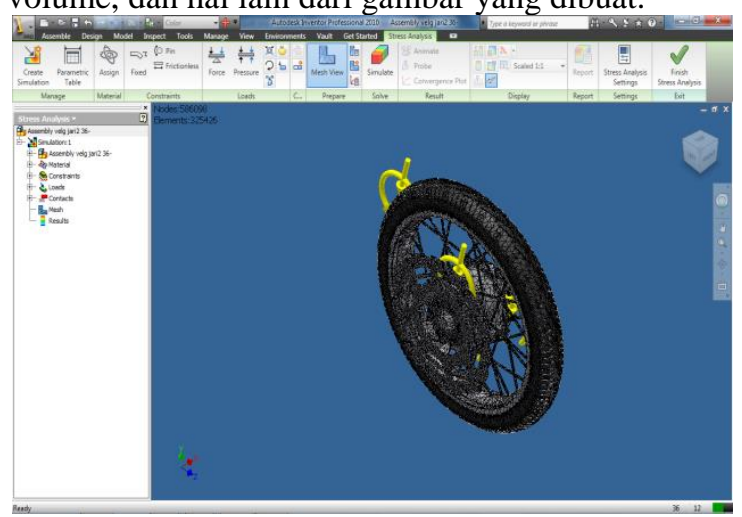

Gambar 15. Mesh view komponen

Setelah gambar berhasil di-Meshing, maka selanjutnya dilakukan simulasi. Klik Simulate Run, maka setelah prosesnya selesai, akan muncul gambar yang merupakan hasil pengujian pembebanan terhadap komponen-komponen yang diuji. Hasil ini meliputi seluruh properti yang ingin diketahui. Properti tersebut dapat diketahui dengan perubahan yang terjadi pada gambar sebelum dan setelah dilakukan pembebanan.

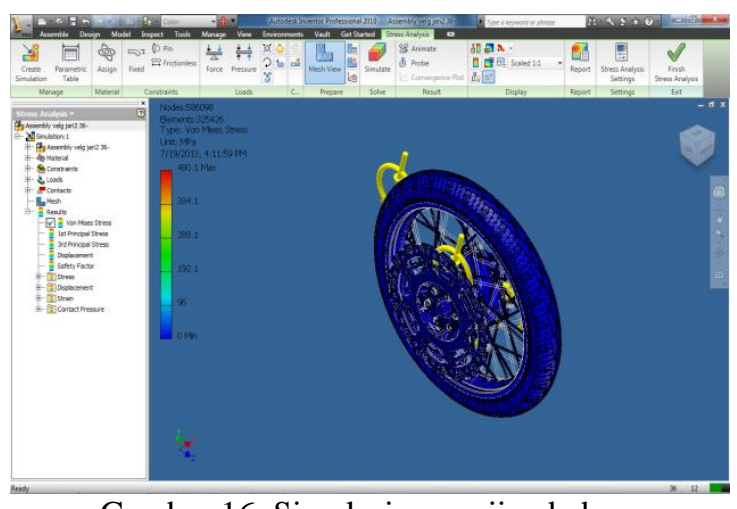

Gambar 16. Simulasi pengujian beban

\section{e. Kesimpulan}

Dalam menentukan tipe velg yang tepat digunakan untuk sepeda motor diperlukan sebuah faktor penentu yang dapat dijadikan sebagai acuan berdasarkan hasil pengujian beban pada kedua jenis velg. Faktor tersebut merupakan faktor keamanan velg tersebut setelah dilakukan pengujian. Ditinjau dari faktor keamanan pada material yang digunakan untuk velg sepeda motor hybrid harus lebih besar daripada 1,0 jika harus dihindari kegagalan. Faktor keamanan yang digunakan pada velg sepeda motor hybrid dihitung berdasarkan perbandingan tegangan luluh (Yield Strenght) material steel untuk velg jari-jari dan aluminium (cast) untuk velgracing dibagi dengan tegangan von mises maksimum dari hasil pengujian menggunakan software Autodesk Inventor. Perhitungan faktor keamanan tersebut dihitung dengan menggunakan rumus sebagai berikut:

$$
\text { Faktor of Safety }(\eta)=\frac{s y}{\sigma e}
$$

Sy=Tegangan luluh material Steel sebesar 207 $\mathrm{MPa}$ (velg jari-jari) dan Aluminium-6061 sebesar $275 \mathrm{MPa}$ (velgracing)

$\sigma e=$ Tegangan Von Mises dari hasil pengujian (untuk velg jari-jari dan velgracing hasilnya berbeda-beda tiap tipenya) 


\section{HASIL DAN PEMBAHASAN}

a. Hasil StressAnalysis dengan Tipe Beban Force Untuk Velg Jari-jari dan VelgRacing pada Software Autodesk Inventor

Setelah mengikuti langkah-langkah pengujian seperti pada bab 3, maka akan muncul hasil perhitungan yang dilakukan dengan Metode Elemen Hingga pada software Autodesk Inventor. Pengujian dilakukan dengan memasukkan beban mulai dari $1500 \mathrm{~N}$ sampai $3000 \mathrm{~N}$. Beban diberikan pada bagian tengah ban dan bagian tromol velg.

Faktor keamanan untuk kedua jenis velg dan tipenya menentukan apakah velg tersebut cocok dipakai untuk sepeda motor hybrid. Faktor keamanan harus lebih besar dari 1,0, hasilnya sebagai berikut:

Tabel 1. Perhitungan Faktor Keamanan (SafetyFactor) Untuk Pengujian Force

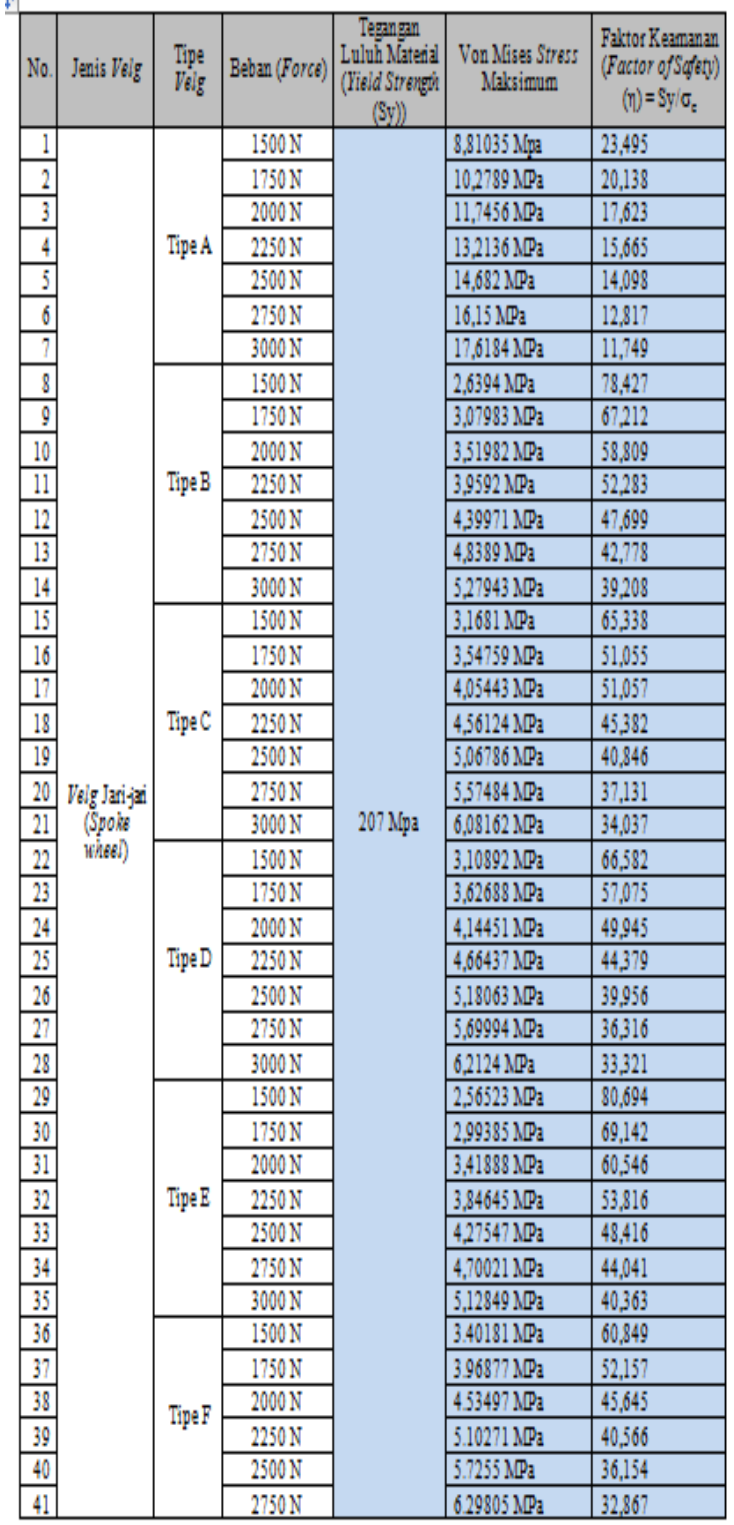

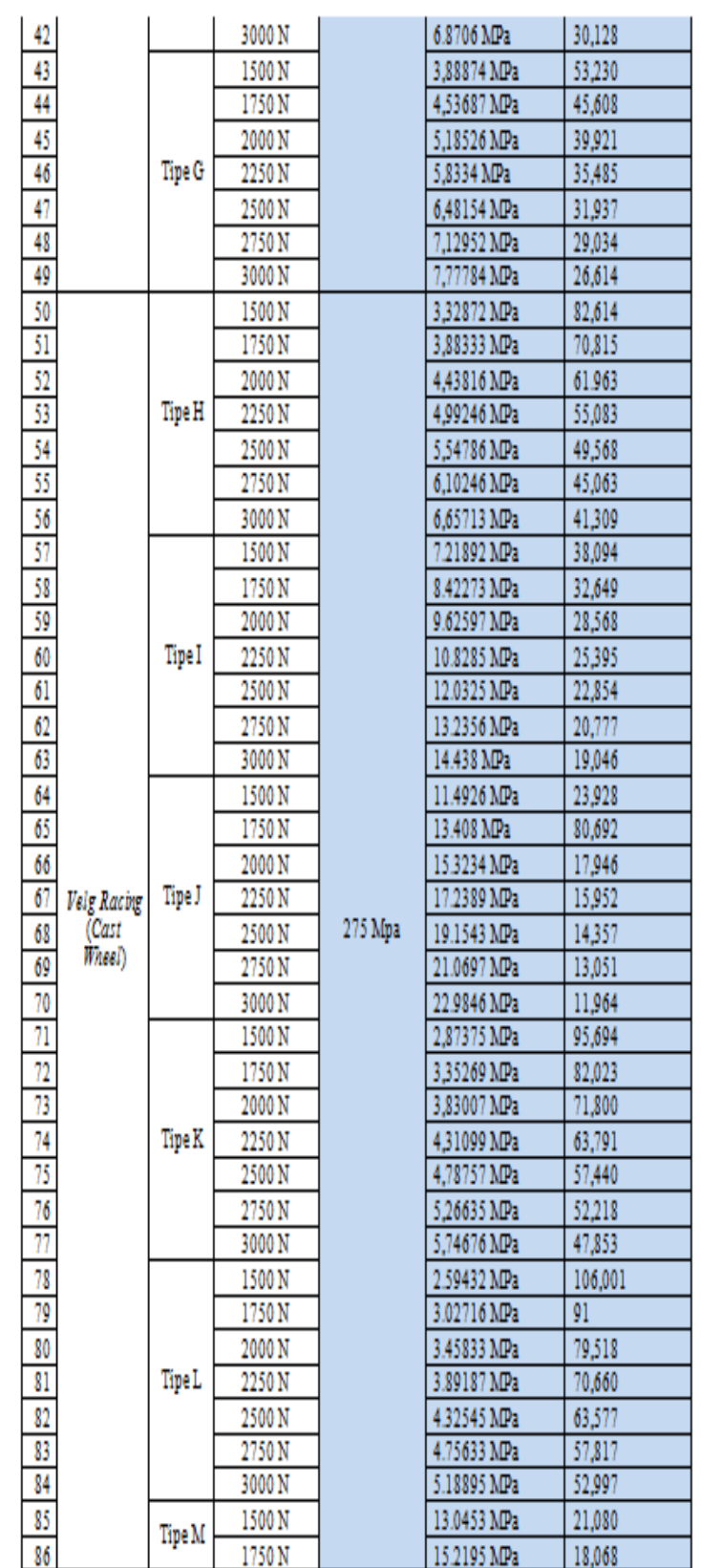

Berdasarkan hasil perhitungan diatas, faktor keamanan untuk semua tipe velg berada diatas angka 1,0 sehingga dapat disimpulkan, untuk pembebanan Force mulai dari 1500 N sampai 3000 $\mathrm{N}$ berada pada posisi aman dan dapat digunakan sebagai velg sepeda motor hybrid. Pembebanan ini mengasumsikan velg diberi beban secara statis (dalam keadaan diam).

\section{b. Hasil StressAnalysis dengan Tipe Beban Force dan Momen Untuk Velg Jari-jari dan VelgRacing pada Software Autodesk Inventor}

Pengujian ini memiliki langkah yang sama dengan pengujian yang pertama, perbedaannya pada penambahan Moment. Pada tahap ini, velgdiasumsikan pada kondisi diberi beban statis 
(Force) sekaligus diberi beban dinamis (Moment) yang mengakibatkan roda dapat berputar. Beban Force yang diberikan sebesar $3000 \mathrm{~N}$ dan Moment mulai dari 5000 N.mm hingga 30.000 N.mm. Hasil pengujian ini juga menunjukkan data yang lengkap dan terperinci sehingga dapat dilakukan analisis selanjutnya. Berikut ini adalah hasil pengujian Force ditambah dengan Moment, yaitu:

Pengaturan dan material yang digunakan pada pengujian kedua ini sama dengan yang digunakan pada pengujian pertama. Untuk langkah selanjutnya, perlu dianalisa juga faktor keamanan dari semua tipe velg dengan menggunakan rumus yang sama seperti pada pengujian sebelumnya. Maka dapat dilihat hasil dari perhitungan faktor keamanan sebagai berikut:

Tabel 2. Perhitungan Faktor Keamanan (SafetyFactor) Untuk Pengujian Force dan Moment

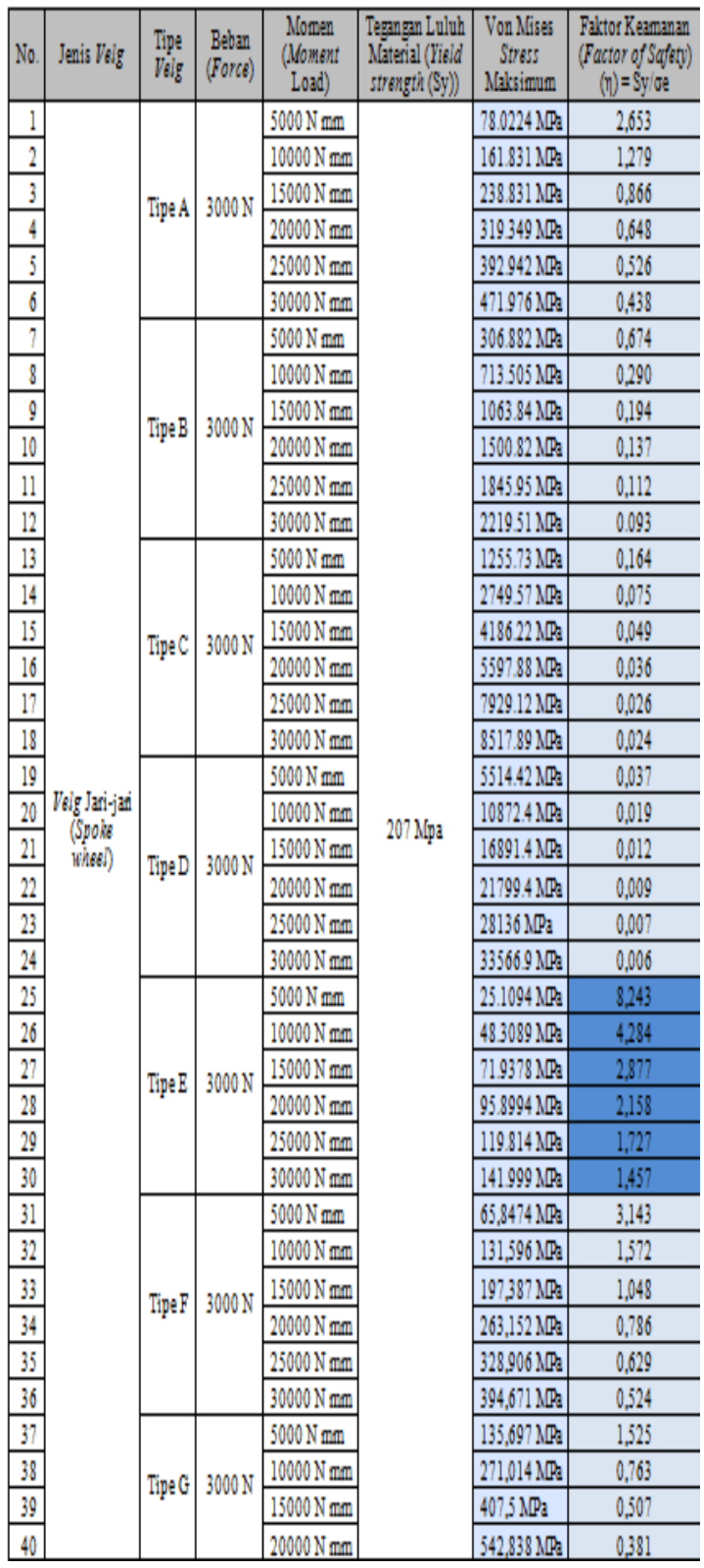

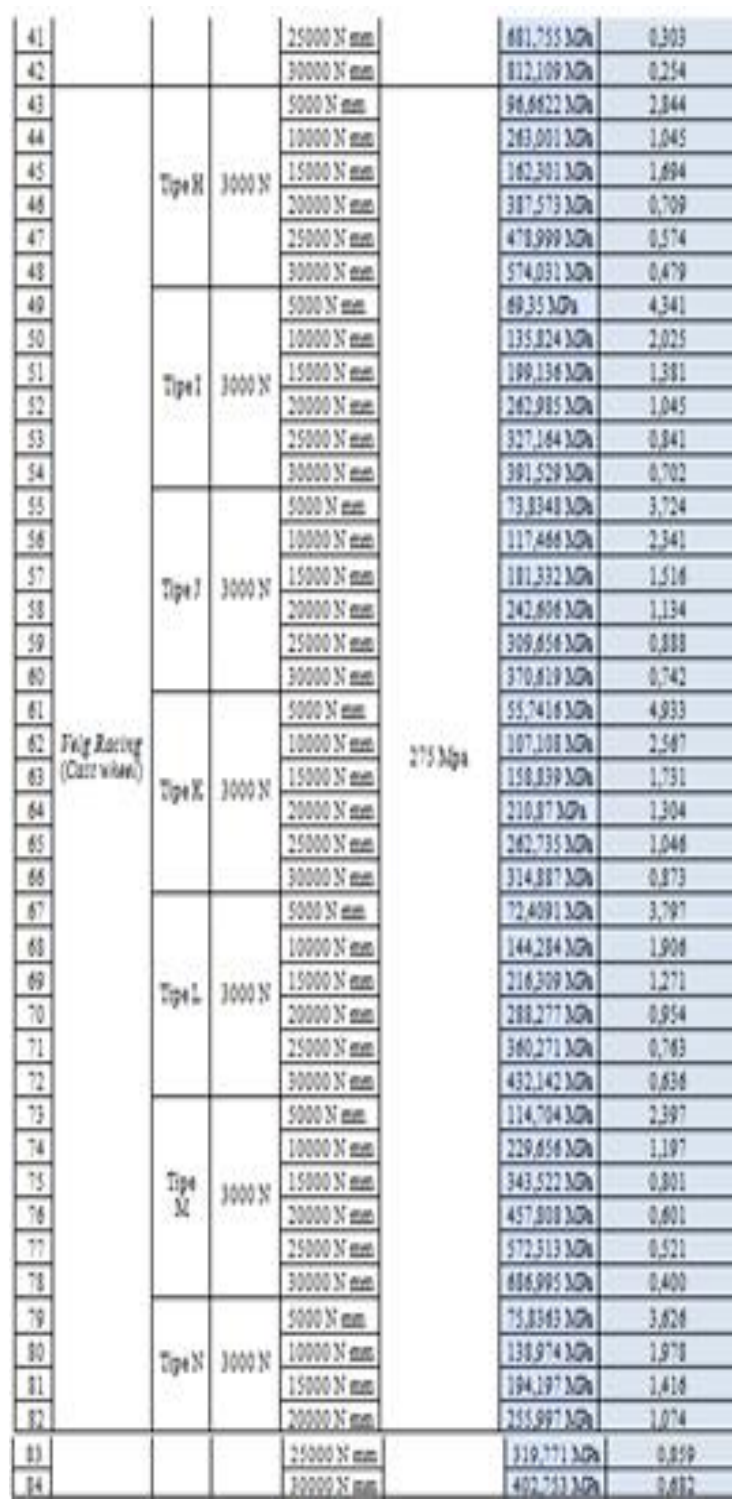

Dari tabel diatas, dapat terlihat bahwa velg yang mempunyai faktor keamanan diatas 1,0 adalah velg jari-jari tipe E. Beban Force yang diberikan sebesar $3000 \mathrm{~N}$ dan Moment sebesar 30.000 N.mm memiliki hasil faktor keamanan 1,457 sehingga dapat disimpulkan bahwa velg jarijari tipe E dengan jumlah jari-jari 64 buah dapat digunakan pada sepeda motor hybrid dengan aman.

\section{KESIMPULAN}

Software Autodesk Inventor dapat memudahkan proses perencanaan desain sekaligus pengujian velg sepeda motor hybrid. Software ini mampu mengitung tegangan dan regangan serta perhitungan lain dengan membuat asumsi sehingga sesuai kondisi sebenarnya atau yang ingin dibutuhkan dapat bekerja dengan baik. Pemiihan material juga cukup lengkap dan sudah dibuat berdasarkan standar yang telah ditetapkan. Hasil dari pengujian ini dijelaskan dengan sangat jelas 
dan terperinci sehingga dapat dipahami dengan mudah.

Hasil pengujian yang telah dilakukan ke semua jenis dan tipe velg membuktikan bahwa velg jarijari tipe E dapat dijadikan pilihan sebagai velg sepeda motor hybrid. Von Mises Stress yang terjadi pada velg tipe $\mathrm{E}$ dalam pengujian beban Force sebesar $3.000 \mathrm{~N}$ dan Moment sebesar 30.000 N.mm menunjukkan tegangan paling kecil dibanding dengan jenis dan tipe velg lain. Velg jari-jari tipe $\mathrm{E}$ memiliki 64 buah jari-jari sebagai penghubung antara velg dengan tromol. Material yang digunakan velg tipe $\mathrm{E}$ adalah material Steel dengan tegangan luluh sebesar $207 \mathrm{MPa}$. Komponen pendukung pada velg sepeda motor hybrid adalah sama dan digunakan untuk semua jenis dan tipe velg.

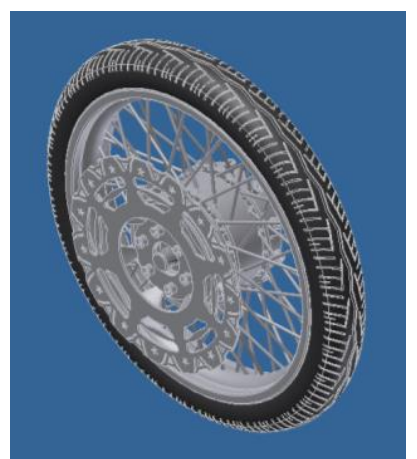

Gambar 17. Velg Jari-jari Tipe E (64 jari-jari)

\section{DAFTAR PUSTAKA}

Alchazin, Syaiful A.B. Modul Training Autodesk Inventor 2012. Bogor: Lembaga Penerbangan dan Antariksa Nasional, 2011.

Ambiyar. Teknik Pembentukan Pelat Jilid 1. Jakarta: Departemen Pendidikan Nasional, 2008.

Arah Sarana Tbk., Multistrada. Buku Pengetahuan Ban Penumpang. Jakarta: Multistrada Arah Sarana Tbk, 2011.

Djaprie, Sriati. Peningkatan Keuletan Paduan Al yang Ditekan, Ditarik, dan Dirol. Jakarta: Jurnal Universitas Indonesia, 1982.

Effendi, Agus. Pengaruh Beban Dan Tekanan Udara Pada Distribusi Tegangan Velg Jenis Lenso. Jakarta: Jurnal Universitas Gunadharma, 2007.

Firmansyah. Analisis Statik Rangka Motor Hybrid Menggunakan Software Catia V5. Jakarta: Jurnal Universitas Gunadharma. 2007.

Gere, James M. dan Stephen P. Thimosenko. Mekanika Bahan Jilid 1. Jakarta: Penerbit Erlangga, 1996.

Giancoli, Douglas C. Fisika Edisi Ke 5. Jakarta: Penerbit Erlangga, 1999.
Jama, Jalius dkk. Teknik Sepeda Motor Jilid 3 SMK. Jakarta: Departemen Pendidikan Nasional, 2008.

Listijorini, Erny. Pengembangan Teknologi Pengedali Switching pada Kendaraan Hybrid Roda Dua. Surabaya: Jurnal Institut Teknologi Surabaya, 2010.

M.A, Lexy Moleong. Metodologi Penelitian Kualitatif-Edisi Revis. Bandung: PT Remaja Rosdakarya, 2007.

Ngadiyono M.Pd., Yatin. Modul Pembelajaran Autodesk Inventor. Yogyakarta: Fakultas Teknik Universitas Negeri Yogyakarta, 2011.

Nugraha S.Pd.T., Beni Setya. Chasis Sepeda Motor. Yogyakarta: Fakultas Teknik UNYJurusan Pendidikan Teknik Otomotif, 2005.

Pisa, Billy Fernando. Karakteristik Tegangan dan Deformasi Maksimum dengan Berbagai Jumlah Spoke pada Velg Cast Wheel. Surabaya: Universitas Kristen Petra, 2011.

Prasetyo, Bambang dan Lina Miftahul Jannah, Metode Penelitian Kuantitatif Teori dan Aplikasi. Jakarta: PT. Raja Grafindo Persada, 2007.

Riduwan. Belajar Mudah Penelitian untuk GuruKaryawan dan Peneliti Pemula. Bandung: Alfabeta, 2009.

Rivanto, Robby. Pengaruh Tekanan Ban dan Beban pada Roda terhadap Traksi Maksimal Roda Penggerak. Surabaya: Universitas Kristen Petra, 2009.

Santoso, Puguh. Analisis Tegangan Statik Pada Rangka Sepeda Motor Jenis Matic Menggunakan Software Catia P3 V5rl4. Jakarta: Universitas Gunadharma, 2009.

Seprianto, Dicky. Perancangan Alat Blending/Mixing Menggunakan Perangkat Lunak Cad Autodesk Inventor Professional 2010. Palembang: Jurnal Politeknik Negeri Sriwijaya, 2011.

Setiadi, Riany Chandra. Analisa Tegangan Pada Pressure Vessel Horizontal Dengan Menggunakan Metode Elemen Hingga. Surabaya: Universitas Kristen Petra, 2005.

Shigley, Joseph Edward. Perencanaan Teknik Mesin Jilid 1. Jakarta: Penerbit Erlangga, 1994.

Supriatna, Budi. Analisa Perawatan dan Perbaikan Sepeda Motor Honda Absolute Revo 2009 dengan Metode FMEA. Jakarta: Universitas Mercubuana, 2011.

UNY, Jurusan Teknik Mesin. Modul 6 Assembly Modelling Fundamental. Yogyakarta, Universitas Negeri Yogyakarta, 2006.

Wasono, Antonius Bowo. Teknik Teknik Grafika dan Industri Grafika Jilid 1 SMK. Jakarta: Departemen Pendidikan Nasional, 2008. 